\title{
Cannabinoids as a yield modifier in physical activit: A systematic review characters
}

\author{
Leonardo Tibiriçá Corrêa', Juliana Weckx Peña Muñoz ${ }^{6}$, \\ Beatriz do Prado Pacca Faria ${ }^{2}$, Jeferson Santana ${ }^{6}$, Leandro \\ Yanase $^{6}$, Esther Lopes Ricci ${ }^{3-5}$, Lorena de Paula Pantaleon ${ }^{5}$, \\ Leonardo Ribeiro de Paula ${ }^{5}$, Guilherme Mendes Ribeiro ${ }^{5}$, \\ Vinicius Barroso Hirota ${ }^{6}$ and André Rinaldi Fukushima ${ }^{4-6 *}$
}

\author{
1'Departamento de Farmacologia Instituto de Ciências Biomédicas Universidade de São Paulo, Av. \\ Prof. Lineu Prestes, 1524, SP, Brazil \\ 2Universidade Municipal de São Caetano do Sul - Campus Barcelona: Av. Goiás, 3.400 - \\ Barcelona - São Caetano do Sul - CEP: 09550-051, Brazil \\ ${ }^{3}$ Universidade Presbiteriana Mackenzie - CCBS Centro de Ciências Biológicas e da Saúde, \\ Consolação, São Paulo, Brazil \\ ${ }^{4}$ Faculdade de Ciências da Saúde IGESP, Departamento de Pesquisa - R. da Consolação, 1025 - \\ Consolação, SP, Brazil \\ ${ }^{5}$ Faculdade de Medicina Veterinária e Zootecnia da Universidade de São Paulo - Av. Prof. Dr. \\ Orlando Marques de Paiva, 87 - Butantã, SP, Brazil \\ ${ }^{6}$ Centro Universitário das Américas - FAM - R. Augusta, 1508 - Consolação, São Paulo - SP, \\ 01304-001, Brazil
}

\section{More Information}

*Address for Correspondence:

André Rinaldi Fukushima, Department of Pathology, School of Veterinary Medicine and Animal Science, University of São Paulo (USP), São Paulo, SP 05508-010, Brazil,

Tel +5511981337311; Email: fukushima@usp.br

Submitted: July 19, 2021

Approved: July 27, 2021

Published: July 28, 2021

How to cite this article: Corrêa LT, Muñoz JWP, Faria BP, Santana J, Yanase L, et al. Cannabinoids as a yield modifier in physical activit: A systematic review characters. J Sports Med Ther. 2021; 6: 018-021. DOI: 10.29328/journal.jsmt.1001053 ORCiD: orcid.org/0000-0001-6026-3054 Copyright: @ 2021 Corrêa LT, et al. This is an open access article distributed under the Creative Commons Attribution License, which permits unrestricted use, distribution, and reproduction in any medium, provided the original work is properly cited.

Keywords: Marijuana; Physical activity; Competition; Doping

Check for updates

OPEN ACCESS

\section{Abstract}

Marijuana is considered illicit in much of the world, and is classified as a drug for recreational use, in recent decades the medicinal use of Cannabis sativa L. has grown and diversified, being considered the only therapeutic alternative in the control of serious and incurable diseases such as syndrome of Dravet. The world panorama has shown a more liberal position, since in several countries such as the United States of America, Holland, Australia, Italy, and more recently in Canada, the use of medications, or even the recreational use of this plant, have been regulated. In this context, the investigation of the modifying effects on physical activity of empirically used cannabinoids is fundamental nowadays, mainly due to the regulatory recognition of Cannabis sativa $\mathrm{L}$. as a medicinal plant in a large part of the world. Therefore, the objective of this review was to verify the evidence related to the effect of cannabis on physical performance and to identify and highlight the challenges in the interpretation of information regarding the performance of practitioners of physical activity, as well as athletes, presenting new trends in this area of research to be addressed. To carry out the systematic review, a bibliographic survey of case reports was obtained through Pubmed, Science Direct and Google Academic databases. The following keywords were used to perform the research: cannabis, performance, pain, competition. The following filters were used as inclusion criteria a languages used english; species: humans; types of articles: original articles and reviews and period of publication of articles: 1981 to 2021.

\section{Introduction}

The medicinal and recreational use of cannabis (marijuana) is undergoing extensive regulatory review in many global jurisdictions. Tetrahydrocannabinol (THC) is the main psychoactive component of cannabis [1-3] the component considered pharmacologically active is cannabidiol (CDB). With the development of scientific research and the advent of semi-synthetic and synthetic drugs, the availability of these substances increased, and their abuse or misuse became a public health problem [31].
Considered illegal in much of the world, marijuana is classified as a recreational drug. Thus, the anti-doping tests for it are performed only in competition periods, as is also the case with cocaine. Both included in the World Anti-Doping Agency's list of prohibited substances [4]. Interestingly, cannabinoids, which are the organic chemical compounds of the marijuana plant, fall into the (S8) class of stimulants on that list, including tetrahydrocannabinol (THC) and some of its analogues, sold in pill form [4].

The problem of drug use among athletes of different levels 
has increased in recent years. According to the latest UNODC report that presented data for the year 2017 in the United States and Europe, alcohol tops the list of users and marijuana appears in second place, ahead of tobacco (UNODC, 2017). Cases of high-level athletes in the modes of snowboarding, swimming, judo, among others, and the use of this substance are frequently reported to the media.

Cannabinoids derived from cannabis can be administered by various routes, such as smoked or ingested for a variety of medical and non-medical reasons [5].

The use of cannabis has overcome the most distinct barriers, and is mainly associated with the cultural change experienced by modern society characterized by constant competition, strenuous intellectual workload, environmental exposure to pollutants, high urbanity and social deprivation [6].

Notwithstanding this, its use reached even athletes and practitioners of physical activity, generating a potential impact on their health, as well as on their performance both in training and in competition [1,6-8].

WHO (2020), and Caspersen (1985) et al. [9,10] defined physical activity as beeing "as any bodily movement produced by skeletal muscles that results in energy expenditure. The energy expenditure can be measured in kilocalories. Physical activity in daily life can be categorized into occupational, sports, conditioning, household, or other activities".

Its therapeutic use in physical activity practitioners can vary from its application in the management of chronic pain [2,7,8,11-13], even in anti-inflammatory use [2,7,11-13] or uses as orexigen. Although there is evidence of serious harm caused by cannabis use on the health of athletes, descriptions of these cases are poorly described in the scientific literature, therefore, one should be aware of the potential for abuse and damage to mental health that cannabis abuse can cause $[1,14,15]$.

There is no well-established scientific report on the prevalence of cannabis use among elite athletes, its use is associated with certain high-risk sports [13].

There is no evidence of the use of cannabis as a modifier to improve performance [16], however its analgesic, antiinflammatory, orexigenic effects are widely described in scientific literature.

From another perspective, the use of medicinal and recreational cannabis among athletes reflects changes in social and cultural norms and experiences. Although cannabis use is more prevalent in some athletes involved in high-risk sports, there is no direct evidence of performance-enhancing effects in high-risk athletes. This use may be related to the anxiolytic and disturbing characteristics of the CNS that cannabinoids exert under this type of physical activity $[16,17]$.
The potential beneficial effects of cannabis such as analgesia and pain control, including the reduction of concussion-related symptoms, deserve further attention.

Of the studies surveyed, none showed improvement in aerobic performance, in contrast, two studies $[1,3,7,13,18]$ showed harmful effects, showing that cannabis use generated angina with a lower workload and reduced strength in $100 \%$ of those surveyed $[1,3,7,13,18]$. This fact may be associated with paranoid syndrome that presents signs and symptoms similar to panic attacks, such as precordial pain radiating to the head and neck, feeling of imminent death and increased anxiety [30]. The adverse reactions caused by cannabis interrupted, in most cases, the exercise protocol proposed by the studies [1].

The study by Kennedy, [1] showed a relevant finding regarding the relationship between physical exercise and the use of cannabinoids. The findings showed that aerobic exercises were able to generate small increases $(<1 \mathrm{ng} / \mathrm{mL})$ in plasma THC concentrations of physical activity practitioners, however this increase did not impact positively or negatively on the strength parameters or improvement in aerobic performance.

In this context, the objective was to carry out a systematic literature review, relating the findings of the interrelationship of the use of cannabinoids for both medical and recreational purposes and physical exercises for both practitioners and professional athletes.

Studies among elite amateur athletes (NCAA) suggest that the use of illicit drugs, such as cannabis, is mediated by social norms and detection risk [19]. cannabis around the world can play an important role in change. use cannabis patterns among athletes $[20,21]$. Other behaviors reported to be associated with cannabis use include binge drinking and women competing at the international level. It also appears from a study that extreme athletes start experimenting with cannabis at a very young age [22]. Cannabis use among athletes may therefore be more related to social norms of behavior than performance improvement.

\section{Materials and methods}

Therefore, the methodology used in this systematic review was carried out through a bibliographic survey of original articles, review articles and cases reports obtained from the Pubmed, Science Direct, Google Academic, Cochrane, PEDro and Scopus databases. The following keywords were used to perform the research: cannabis, performance, pain, competition The following filters were used as inclusion criterion: Languages: English and Portuguese; Species: human, mouses and rats; Types of articles: originals, reviews and case reports; Period of publication of articles: 1981 - 2021. The decision algorithm can be seen in Figure 1 as Muñoz, et al. 2020 [23]. Publication search was performed by an advanced 


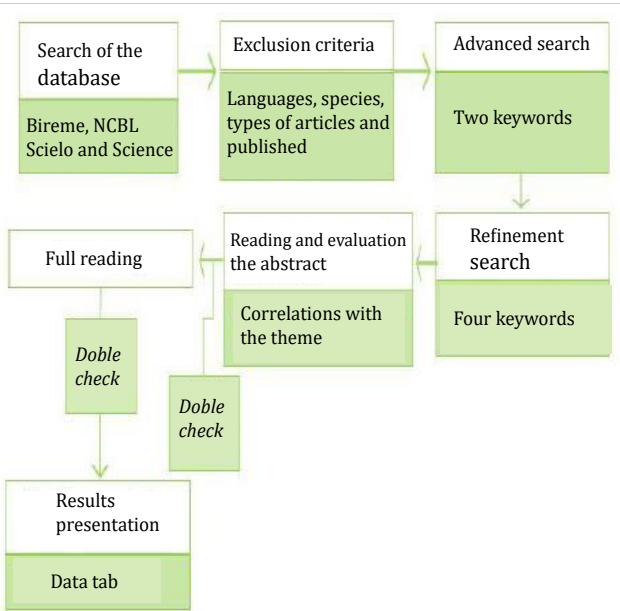

Figure 1: The flowchart of the scientific methodology. Source: Muñoz, et al. 2020 [23].

method in which three key words were correlated, being at least one key word related to cannabis and performance aspects. From all the correlations of used key words, we had retrieved 264 articles. The following exclusion criteria were used: Duplicate articles; Absence of citation of cannabinoids and performance aspects; Articles in other languages; Articles that did not contain original research or reviews.

Remaining articles were examined by reading the abstract and further excluding publications that had no correlation with the key mentioned above. A total of 13 articles met the criteria for inclusion. These articles only cited cannabinoids when correlationated whith performance modification in sports. The analysis of results was performed by tabulating the articles according to the convinient characteristics.

Thus, table 1 shows the reference, publication objective, corresponding results and conclusion, which contributed to the construction of this work.

\section{Results and discution}

Based on the articles found, it was possible to compile the data in Table 1, demonstrating the main interests in the use of Cannabis by an athlete.

Table 1: Relationship of cannabis application with respective mechanisms.

\begin{tabular}{|c|c|c|}
\hline Application & Mechanism of action & Reference \\
\hline Analgesia & $\begin{array}{l}\mathrm{CB}_{1} \text { and } \mathrm{CB}_{2} \text { acting in the modulation of neuropathic and inflammatory pain, mainly in the } \\
\text { pariaqueductal gray matter of the midbrain and in the transmission of pain through the } \\
\text { spinal cord. TRPV-1 agonism may promote peripheral analgesia. }\end{array}$ & {$[2,7,8,11-13]$} \\
\hline Motor disturbance (balance, locomotion, tone) & $\mathrm{CB}_{1}$ receptor in neocortex, striatum, cerebellum & {$[1,7,8,11,13,24]$} \\
\hline $\begin{array}{c}\text { Behavioral disturbance (emotional, sensory, memory, } \\
\text { behavior, awareness) }\end{array}$ & $\begin{array}{l}\text { Receptor } \mathrm{CB}_{1} \text { no neocórtex, bulbo, hipocampo, amígdala, tálamo, hipotálamo, } \\
\text { mesencéfalo e rombencéfalo }\end{array}$ & {$[7,11]$} \\
\hline Heart & $\begin{array}{l}\text { In } \mathrm{CB}_{1} \text {, decreased contractile force, increased systolic and diastolic blood pressure, } \\
\text { increased heart rate, and vasodilation. Precipitation of angina. Pro-inflammatory and } \\
\text { increased fibroblast activity. In } \mathrm{CB}_{2} \text { it produces anti-inflammatory effects. }\end{array}$ & {$[1,3,7,8,13,18]$} \\
\hline Physical performance & Decrease in cardiac work, no change in handgrip strength and forced vital capacity & {$[1,3,13,15,25]$} \\
\hline Aerobic activity & $\begin{array}{l}\text { No change in respiratory flow rate. Induction of bronchodilation in aerobic activity. Quickly } \\
\text { induces fatigue and exhaustion. }\end{array}$ & {$[1,14,15]$} \\
\hline $\begin{array}{c}\text { Anxiolytic (from the point of view of calming down before } \\
\text { or relaxing after playing sports) }\end{array}$ & $\begin{array}{l}\text { Through the activity of } \mathrm{CB} 1 \text { in the limbic and paralimbic systems and effects on the } \\
\text { midbrain dopaminergic pathway producing relaxation, sedation and pleasure }\end{array}$ & {$[6-8,26-29]$} \\
\hline Improved perception and vision & $\begin{array}{c}\text { Cannabis improves visual perception for goalkeepers in soccer, however it can } \\
\text { compromise concentration, attention and cognition. }\end{array}$ & {$[7,11]$} \\
\hline
\end{tabular}

In general, the articles emphasized the injury to sportsmanship, as it poses risks to the health of athletes and hurts the ethical considerations that imply the use of Cannabis, as well as sports values that include honesty, fair play, excellence, fun, commitment and respect. The World Anti-Doping Agency prohibits the use of cannabis by athletes, presenting as a justification the breach of sports values and considering that it is a prohibited drug in many countries around the world.

THC can be detected in urine, however it is a difficult procedure, from an analytical point of view, as it is highly lipophilic and takes weeks to be excreted by the body.

Of sports applications, there is an interest in producing anxiolytic effects for athletes who are tense before any physical activity or later to produce relaxing, analgesic and sedative effects.

In all the articles read, no significant effects were produced on physical performance, whether in aerobic exercise or in the improvement of cardiac work. Instead of demonstrating a benefit from physical activity, it is shown to disrupt cardiac activity, increasing the frequency and decreasing the contractile force, despite inducing bronchodilation during physical activity, it does not improve respiratory flow. It is known as a potent inducer of exhaustion, fatigue, drowsiness, and behavioral and cognitive disturbance. Its benefits are restricted to promoting analgesia and both psychic and muscular relaxation. Huestis, et al. [7] cited that cannabis improves visual perception for goalkeepers in soccer, however it can compromise concentration, attention and cognition.

\section{Conclusion}

Although, according to WADA, 2019 [4] marijuana and cannabinoid derivatives are considered doping and both included on the World Anti-Doping Agency's list of prohibited substances, CBD and cannabinoid derivatives exert a number of physiological, biochemical and psychological effects with the potential to athletes beneficiaries. As listed in this systematic review, there is evidence that cannabinoids have 
anti-inflammatory, neuroprotective, analgesic and anxiolytic activities, in addition to gastroprotective activity. When used in the treatment of inflammation, they can promote an antiinflammatory effect in traumatic musculoskeletal injuries. However, it is important to recognize that these findings are still preliminary. These consulted studies, in general, apply to athletes, who frequently make use of the administration of high doses of cannabinoids. In the central nervous system, studies are examined to investigate how CBD acts on sport performance. However, this review shows that there is a perspective on the use of CBD in the sport context, as it has pharmacological effects on several important physiological systems in the sport environment.

\section{References}

1. Kennedy MC. Cannabis: exercise performance and sport. A systematic review. J Sci Med Sport. 2017; 20: 825-829.

PubMed: https://pubmed.ncbi.nlm.nih.gov/28392338/

2. Fraguas-Sanchez A, Torres-Suarez A. Medical use of cannabinoids. Drugs. 2018; 78: 1665-1703.

PubMed: https://pubmed.ncbi.nlm.nih.gov/30374797/

3. Aronow WS, Cassidy J. Effect of marijuana and placebo-marijuana smoking onangina pectoris. N Engl J Med. 1974; 291: 65-67.

PubMed: https://pubmed.ncbi.nlm.nih.gov/4599385/

4. World Anti-Doping Agency. International Standard for Laboratories. 2009. http://www.wada-ama.org/en/Science-Medicine/Anti-DopingLaboratories/International-Standard-for-Laboratories/

5. Devinsky O, Cross JH, Laux L. Trial of cannabidiol for drug-resistant seizures in the Dravet syndrome. N Engl J Med. 2017; 376: 2011-2020.

6. Saugy M, Avois L, Saudan C, Robinson N, Giroud C, et al. Cannabis and sport. Br J Sports Med. 2006; 40: i13-i15.

PubMed: https://pubmed.ncbi.nlm.nih.gov/16799094/

7. Huestis MA, Mazzoni I, Rabin O. Cannabis in Sport Anti-Doping Perspective. Sports Med. 2011; 41: 949-966.

PubMed: https://pubmed.ncbi.nlm.nih.gov/21985215/

8. Huestis MA, Smith ML. Human cannabinoid pharmacokinetics and interpretation of cannabinoid concentrations in biological fluids and tissues. In: EISohly MA, editor. Marijuana and the cannabinoids. Totowa (NJ): Humana Press. 2006: 205-236.

9. World Health Organization. WHO guidelines on physical activity and sedentary behaviour. World Health Organization. 2020;

PubMed: https://apps.who.int/iris/handle/10665/336656

10. Caspersen CJ, Powell KE, Christenson GM. Physical activity, exercise and physical fitness: definitions and distinctions for health-related research. Public Health Rep. 1985; 100: 126-131.

PubMed: https://pubmed.ncbi.nlm.nih.gov/3920711/

11. Hu S, Mackie K. Distribution of the endocannabinoid system in the central nervous system. In: Pertwee, R. (ed.) Endocannabinoids. Handbook Experimen Pharmacol. 2015; 231: 59-93.

PubMed: https://pubmed.ncbi.nlm.nih.gov/26408158/

12. Woodhams SG, SagarDR, Burston JJ, Chapman C. The role of the endocannabinoid system in pain. Handb Exp Pharmacol. 2015; 227: 119-143.

PubMed: https://pubmed.ncbi.nlm.nih.gov/25846617/

13. Ware MA. Jensen D, Barrette A, Vernec A, Derman W. Cannabis and the Health and Performance of the Elite Athlete. Clin J Sport Med. 2018; 28: 480-484.

PubMed: https://pubmed.ncbi.nlm.nih.gov/30153174/
14. Thaskin DP, Shapiro BJ, Enoch Lee Y, Harper CE. Effects of smoked marijuana in exper-imentally induced asthma. Am Rev Respir Dis. 1975;; 112: 377-386.

PubMed: https://pubmed.ncbi.nlm.nih.gov/1099949/

15. Renaud AM, Cormier Y. Acute effects of marihuana smoking on maximal exercise performance. Med Sci Sports Exerc. 1986; 18: 685-689. PubMed: https://pubmed.ncbi.nlm.nih.gov/3097453/

16. Bolla KI, Brown K, Eldreth D, Tate K, Cadet JL. Dose-related neurocognitive effects of marijuanause. Neurology. 2002;59:1337-1343. PubMed: https://pubmed.ncbi.nlm.nih.gov/12427880/

17. Pertwee RG. Emerging strategies for exploiting cannabinoid receptor agonists as medicines. Br J Pharmacol. 2009; 156: 397-411.

PubMed: https://pubmed.ncbi.nlm.nih.gov/19226257/

18. Ho W, Kelly M. Chapter ten: Cannabinoids in the Cardiovascular System. In: Kendall D, Alexander S (ed.). Cannabinoid Pharmacol. 2017; 80: 329-336.

19. Tricker R, Connolly D. Drugs and the college athlete: an analysis of the attitudes of student athletes at risk. J Drug Educ. 1997; 27: 105-119. PubMed: https://pubmed.ncbi.nlm.nih.gov/9270209/

20. Van Eenoo P, Delbeke FT. The prevalence of doping in Flanders in comparison to the prevalence of doping in international sports. Int $\mathrm{J}$ Sports Med. 2003; 24: 565-570.

PubMed: https://pubmed.ncbi.nlm.nih.gov/14598191/

21. Peretti-Watel $P$, Lorente FO. Cannabis use, sport practice and other leisure activities at the end of adolescence. Drug Alcohol Depend. 2004; 73: 251-257.

PubMed: https://pubmed.ncbi.nlm.nih.gov/15036547/

22. Brisola-Santos MB, Gallinaro JG, Gil F, Sampaio B Jr, Marin MCD, et al. Prevalence and correlates of cannabis use among athletes-a systematic review. Am J Addict. 2016; 25: 518-528. PubMed: https://pubmed.ncbi.nlm.nih.gov/27629700/

23. Muñoz JWP, Machado TF, Luz J, Bello SG, Ricc EL, et al. Bone Graft as an Adjunctive Treatment for Delayed Union and Non-Union of Fractures in Dogs: Systematic Review Global J Vet Care Res. 2020; 1: 1-7.

24. Glass M, Dragunow M, Faull RL. Cannabinoid receptors in the human brain: a detailed anatomical and quantitative autoradiographic study in the fetal, neonatal and adult human brain. Neuroscience. 1997; 77: 299-318.

PubMed: https://pubmed.ncbi.nlm.nih.gov/9472392/

25. Steadward RD, Singh M. The effects of smoking marihuana on physical performance. Med Sci Sports. 1975; 7: 309-311.

PubMed: https://pubmed.ncbi.nlm.nih.gov/1235156/

26. National Drug Strategy. Cannabis in Australia: use, supply and responses. Monograph Series no. 57. Canberra (ACT): Australian Government, Department of Health and Ageing, 2006.

27. European Monitoring Centre for Drugs and Drug Addiction (EMCDDA) A cannabis reader: global issues and local experiences. Monograph, series 8, Volume 2. Lisbon: EMCDDA, 2008.

28. Moreira FA, Lutz B. The endocannabinoid system: emotion, learning and addiction. Addict Biol. 2008; 13: 196-212.

PubMed: https://pubmed.ncbi.nIm.nih.gov/18422832/

29. National Drug Strategy. Cannabis and mental health: put into context. Monograph Series no. 68. Canberra (ACT): Australian Government, Department of Health and Ageing, 2008.

30. Spechlera PA, Orr CA, Chaarani B, Kan KJ, Mackey S, et al. Cannabis use in early adolescence: Evidence of amygdala hypersensitivity to signals of threat. Dev Cogn Neurosci. 2015; 16: 63-70. PubMed: https://pubmed.ncbi.nlm.nih.gov/26347227/

31. Cordell GA. Sustainable drugs and global health care. Quím Nova. 2009; 32. 